University of South Florida

DIGITAL COMMONS

Digital Commons @ University of

@ UNIVERSITY OF SOUTH FLORIDA

South Florida

Academic Services Faculty and Staff

Publications

Tampa Library

2014

\title{
The Florida State Libraries Resource Sharing Initiative: Did the Predictions Pan Out?
}

\author{
LeEtta M. Schmidt \\ University of South Florida, Imschmidt@usf.edu \\ Dennis Smith \\ Brandeis University
}

Follow this and additional works at: https://digitalcommons.usf.edu/tlas_pub

Part of the Library and Information Science Commons

\section{Scholar Commons Citation}

Schmidt, LeEtta M. and Smith, Dennis, "The Florida State Libraries Resource Sharing Initiative: Did the Predictions Pan Out?" (2014). Academic Services Faculty and Staff Publications. 171.

https://digitalcommons.usf.edu/tlas_pub/171

This Article is brought to you for free and open access by the Tampa Library at Digital Commons @ University of South Florida. It has been accepted for inclusion in Academic Services Faculty and Staff Publications by an authorized administrator of Digital Commons @ University of South Florida. For more information, please contact digitalcommons@usf.edu. 


\begin{abstract}
This article revisits discussion from "The Florida State Libraries Resource Sharing Initiative: Unity Among a Disparate Group" (2012) on the implementation of a new resource sharing program within the Florida State University Libraries called UBorrow. The program and it's effects are assessed after two years with comparison to the project launch's original predictions.
\end{abstract}

Keywords: Resource Sharing, ALEPH, ILLiad, Statewide Programs, Interlibrary Loan, shared collections, consortial resource sharing, remote circulation 


\section{Introduction}

Consortial resource sharing services have been a primary objective for many libraries as they seek ways to expand their patrons' access to collections. Many libraries have focused on the possibilities of such a service as a means to provide access and ensure cost effectiveness while looking for more efficient delivery of materials to patrons. UBorrow was developed as a consortial resource sharing program through the State Universities Libraries (SUL) of Florida. This program was based on the Interlibrary Loan component of the Ex Libris ALEPH Integrated Library System (ILS). The eleven participant state university libraries all utilize the ALEPH system with centralized support for the system and UBorrow program provided by the Florida Center for Library Automation (FCLA).

This article revisits discussion from "The Florida State Libraries Resource Sharing Initiative: Unity Among a Disparate Group" (2012) which discussed the creation, testing and implementation of a new resource sharing program within the Florida State University Libraries called UBorrow. The UBorrow development group, consisting of delegates from each of the eleven state university main, health, and law libraries, tested possible systems and workflows and compiled a list of policies for program launch. The development group predicted that the new UBorrow service, with unmediated request sending and automated availability checks would be faster and create less work for library staff than the traditional interlibrary loan systems in place throughout the state. They also predicted that 30 to $40 \%$ of total traditional interlibrary loan request traffic would be diverted to this unmediated local system, which would ease burden on staff and save money (Schmidt and Smith, 2012).

This resource sharing program was tested in spring 2012 with a soft launch during the summer academic period. Full launch was done at the beginning of the 2011-12 academic year. Uborrow, similar to other statewide programs such as OhioLink and GIL Express, enjoyed significant praise from patrons while requiring moderate additional staff workload and 
challenges to the system's operations.

\section{Literature Review}

The rising importance of electronic materials to researchers versus the declining use of print materials in the library is an oft discussed topic among library practitioners. Niu, Hemminger et al conducted a survey of academic researchers to understand the way they search for information to support their research (2010). One of the findings of this survey is that the majority of researchers preferred using print as well as electronic formats while fewer preferred one over the other (Nui, Hemminger et al, 2010). This may be one of the reasons many libraries continue to develop and expand cooperative and consortial resource sharing services to provide access to print materials while concentrating their acquisitions money on electronic materials. UBorrow's goals were to provide researchers and students with access to the combined collections of the state universities via a unified and cost effective service (Schmidt \& Smith, 2012). The continued success of statewide programs, such as OhioLink and Gil Express, continue to encourage the development of other statewide cooperative programs. Cook and Smith described the growth of OhioLink to include various libraries across Ohio that provided access to materials beyond researchers' and students' home institutions (2011). Gil Express is a highly successful resource-sharing service that includes 35 state institutions belonging to the University Systems of Georgia (Smith, 2012). As seen in OhioLink and Gil Express, these statewide programs are often facilitated by a common Integrated Library System (ILS). UBorrow, OhioLink and Gil Express libraries all shared a common ILS, ALEPH by Ex Libris (Schmidt \& Smith, 2012)(Cook \& Smith, 2011)(Smith, 2012).

In addition to a state sponsored university programs, farther reaching cooperative organizations continue to develop programs that expand access to library materials without dependence on a common ILS system. The Pennsylvania Academic Libraries Consortium created a union catalog and E-Z Borrow program for their members which provided a statewide program originally independent of the state university system (Fennewald, 2005). Consortiums 
are often involved in the negotiation of agreements for electronic material at enhanced member pricing. The success of lending programs and consortial contract agreements can be seen as driving factors in developing the future of resource sharing programs such as e-book sharing. The Boston Library Consortium (BLC) has begun an E-Book pilot program that allows its 17 university and research library members to collectively purchase and use E-Books (BLC, 2012). The possibility of expanding consortial borrowing activities into lending of E-Books, combined with the demonstrated success of print material lending, ensure that programs like UBorrow will continue to be a significant resource for researchers and students.

\section{Background}

The Florida State University Libraries' (SUL) leadership group, the Council of State University Libraries (CSUL), conceptualized the creation of an unmediated borrowing service (FCLA, 2009) that would eventually be named UBorrow. The UBorrow resource sharing development team, made of members from all participant libraries, initially reviewed two possible systems to support the new program. This review included a recently upgraded ILS ALEPH version 19 and the current ILLiad system by Atlas Systems (FCLA, 2009). The development team selected the ALEPH ILL module as the system for the UBorrow service (Schmidt and Smith, 2012). The SULs already had a shared Union Catalog, which would be used as the patron interface for the new resource sharing program, and all the institutions used the same statewide courier services for interlibrary loan material transfer, which was thoroughly evaluated by the development team to assess its ability to absorb an increase in traffic while still guaranteeing timely delivery of materials.

Initial goals for the UBorrow service included enhancements to the catalog to better direct patron requests, allow full automation of lending request processing and make sure every institution had courier service five days a week to speed delivery. Prior to launch, the participating libraries agreed on a set of policies that would standardize the service and patron interaction with the request process. Policies regarding lost and overdue materials were put on 
hold until after the program had generated enough data to support an argument on whether or not a transfer of funds between institutions would be necessary.

\section{Outcomes}

\section{The First Year}

Enhancements to the catalog continued long after full launch in August 2011. Great discussion was had among the development group as to whether the UBorrow request button should be shown on items that were not 'UBorrow-able.' One view was that it would better direct patrons only to UBorrow-able items and not give them the incorrect impression that UBorrow could support their request. An opposing argument was made for making the UBorrow request button more of an all request button. In this scenario, the button on records that were not 'UBorrow-able' would direct the patron to traditional ILL requesting, using ILLiad's OpenURL feature. Patrons would never hit a wall in the system where they could see what they wanted, but not be shown how to ask for it. The simplest option was limiting the UBorrow request button to 'UBorrow-able' material only.

After two years of UBorrow service, full lending automation among all the libraries had still not been obtained. This was primarily due to individual participants desiring more control over when and where request pull slips printed. The ideal pull slip situation involved automated printing one or more times a day on a designated printer; staff or student workers would retrieve the print outs and fetch the material. In this scenario, noting on the requests that the items are on their way would be the first time any library staff would have to interact directly with the system. However, many libraries wanted to fit printing times into their staff's workflow, and required staff to log in to the UBorrow system in order to manually send the print command before materials could be fetched from the stacks. In addition to the timing of the pull slips, some libraries wanted to use removable adhesive labels instead of paper pull slips that would become book bands. Additional work had to be done in the UBorrow system, post program launch, to develop this option. Budget restrictions also kept those libraries that had less than 5 
day per week courier pick up from changing their courier contracts. UBorrow remained far from the function for which it was intended.

Additional work was also done to automate what began as a manual processing of renewal requests. Similar to traditional Interlibrary loan, a patron would send a renewal request, via their web accessible library account, that then had to be forwarded by his/her borrowing library to the lending library. The lending library would determine whether or not to approve the request and send their response, which would then be transmitted back to the patron. This excess of processing, spurred on discussion in the group on whether or not to extend the standard loan period from 30 to 60 days (Shrauger, Radnor, Schmidt, 2012). A longer loan period would result in less renewal requests made by patrons and thus less work. Though the loan period among the group was eventually changed to 60 days in September of 2012, work in the system to automate the renewal request process continued and eventually saw success. If an item had no other requests or holds in the system when the patron requested the renewal, that request would bypass any borrowing library processing and automatically update in the lending libraries system.

There was a total of 9,660 requests sent through the UBorrow system during the soft launch period of March 1, 2011 to August 1, 2011. Requests were automatically routed to the libraries where the item was currently available, and, because of this, many libraries were able to provide materials for a high percentage of incoming lending requests. However, when examining lender answers as to whether they could supply material, the average fill rate was just 54\%. It appeared as though materials were being supplied by approximately three quarters of participating libraries, while the remaining quarter consistently denied requests. This trend continued through the first year of launch and only rose by $3 \%$ in the following year.

It was hoped that using real time availability checks and automating lending processes, book delivery would be faster than traditional ILL. This proved true as the average UBorrow delivery time in 2012 was just 4.11 days, 59.73\% faster than average ILL book delivery time at 


\subsection{1 days.}

$<$ Fig. 1.1>

During the first year of full program launch patrons were given the option of commenting on the service at the point of request. A total of 300 responses were collected between March 2011 and the end of January 2012. Of those comments, more than half were positive, cheering the ease of requesting and speed of delivery. None were negative. Patrons' satisfaction with the increased speed of the service indicated that the UBorrow automations in place were doing their job of simplifying the process.

Figure 1.1 also shows that $30 \%$ of patron comments included extra instructions like emailing a different address than was on record or delivering to a campus address; $11 \%$ included questions about pick up locations, reserve and suggested purchases. These questions and comments were forwarded on to UBorrow sites for follow-up, but may indicate an area where the service could be improved with a more accessible FAQ and instructions for contacting a specific UBorrow site.

$<$ Fig.1.2 >

The development group forecasted a decline in traditional interlibrary loan traffic after the launch of UBorrow. Investigation before the launch indicated that $30 \%$ of all interlibrary loan transactions at any one of the SULs occurred within the group. After a full launch and marketing campaign, the assumption was that this $30 \%$ of requests would move over to UBorrow. There was also an opinion within the group that resource sharing traffic in general, (i.e. the combination of ILL and UBorrow) would increase as it had with OhioLink after the launch of patron initiated borrowing in 1994 (Cook \& Smith, 2011). Figure 2.1 shows the combined resource sharing traffic between traditional interlibrary loan and UBorrow after the UBorrow service launch until June of 2012. Contrary to expectations, UBorrow does not account for 30\% of overall resource sharing traffic among the institutions. Two example institutions were chosen for a closer look. 
The University of South Florida Tampa library, representative of the larger institutions in the group, services a community of 41,428 students enrolled full time with a $\$ 1.5$ billion budget. Bachelor, Master, and Doctorate degrees are awarded among a total of 237 academic programs (University of South Florida, 2014). Previous to and outside of UBorrow, regular interlibrary loan traffic totals 54,000 requests per year. USF is a net lender with nearly double the amount of lending requests received ( $-36,000$ in $2010 / 11)$ compared to borrowing requests $(-18,000$ in $2010 / 11)$

New College of Florida, representative of the smaller institutions, services an honors community of 832 students enrolled full time with a budget of $\$ 32.9$ million (NCF Fast Facts). Bachelor degrees are awarded from 22 different liberal arts programs (NCF General Catalog). Previous to and outside of UBorrow, regular interlibrary loan traffic totals 8,000 requests per year. NCF is a net borrower with triple the amount of borrowing requests processed $(\sim 6,000$ in 2010/11) compared to lending requests ( 2,000 in 2010/11).

\section{USF numbers}

<Fig. $2.1>$

A year after lauch, the use of UBorrow added to total borrowing traffic at USF, not removed or displaced it. This seems to suggest that the new environment and the marketing efforts associated with the launch of the new service gathered new patrons instead of wooing patrons who already used ILL through ILLiad.

The array of patron use also indicates that new users are finding the service. Though graduate patrons are the primary requesters of both systems, the percentage of undergraduates who used UBorrow in $2011 / 12$ is noticeably different between the two services. $15 \%$ of ILL traffic through ILLiad belonged to undergraduates compared to $25 \%$ of undergraduate traffic in UBorrow.

$<$ Fig. $2.2>$

Lending traffic, in comparison to the previous year, seemed to have been displaced by 
the UBorrow system as predicted. Requests among the SULs for materials simply moved from ILL service through ILLiad to UBorrow service through the ALEPH system.

\section{NCF numbers}

$<$ Fig. $3.1>$

The numbers at New College of Florida show a very different picture. For NCF, UBorrow does appear to have displaced borrowing traffic as well as increased resource sharing traffic overall. The most remarkable spike in resource sharing can be seen in September, the month after full launch.

$<$ Fig. $3.2>$

In contrast, NCF's lending via traditional ILL did not diminish very much at all. Instead, lending traffic from UBorrow nearly doubled the amount of loans from NCF's collection. This hearkens to another concern of the original development group: that demands on the collections of smaller institutions would be most changed.

\section{Years Two and Three}

An early spring 2014 survey of the participating institutions shows that UBorrow processing is dissimilar among the libraries. While UBorrow was initially developed as extended circulation, most institutions locate it in the interlibrary loan department. Most institutions also use the paper pull slips to create book bands for UBorrow items even if they use removable labels for traditional interlibrary loan, or, as one library indicated "would prefer labels" but did not have the workflow established in UBorrow.

A questionnaire to library staff in charge of processing UBorrow was also circulated among the libraries in the fall of 2013. Answers from the participants of this survey are summarized in list of pros and cons for how the system currently functions. Among the benefits of UBorrow were faster turn around and ease of patron requesting, partially aided by the 
patron's familiarity with the catalog interface. Overall, staff across the state saw UBorrow as an improved use of statewide library resources. However, UBorrow was seen as not quite fulfilling its potential. UBorrow's weaknesses were listed as needing more marketing and a better link between UBorrow and other ILL systems. The paperwork and labels are regarded as inefficient and many staff would like greater standardization. Though UBorrow deliveries are reported as faster than interlibrary loan the turnaround time is still not acceptable to staff and the patrons they serve. Similarly unacceptable is patron confusion about ebooks and what items are and are not borrowable in UBorrow. Staff members also pointed out that, though the intentions of UBorrow were admirable, the execution of the service left much to be desired (Resource Sharing Task Force, 2013).

$<$ Fig $4.1>$

The majority of institutions have UBorrow borrowing and lending ratios similar to traditional interlibrary loan rates. The University of Central Florida (CFU in figure 4.1) has configured its instance of the UBorrow catalog to direct patrons to the ILLiad interlibrary loan request management system it uses for traditional ILL service to avoid duplicated workflows, so it's borrowing rates are not shown. The Florida Academic Repository (FLARE; FLR in figure 4.1) was added to UBorrow in the summer of 2013 and has thus far lent under one hundred books. FLARE was constructed to be a shared storage option for low use items among the universities (Florida Academic Repository, 2014). As more libraries send their materials to FLARE, UBorrow use of the collection may increase regardless of the items' low use status at their original owning institution. Among the few universities with UBorrow traffic greatly different from traditional ILL the University of Florida, Florida State University, and New College University's high rates of borrowing to lending illustrate the effect of strong and devoted marketing efforts at those institutions.

$<$ Fig. $4.2>$

UBorrow request traffic in general has plateaued since the launch, as illustrated in figure 
4.2 , with volumes consistently under 20,000 total requests. This could be due to a drop in marketing efforts and increase in project load and distractions as the universities and statewide technical support worked through a legislative mandate to combine technical support for university and college libraries into one organization (FCLA, 2012). For instance, though each library has included the instructive information deemed necessary for their patrons in local web sites, there is currently no shared web page that describes and explains the service available to all patrons of UBorrow. Though the examples of what strong marketing efforts can do at University of Florida, Florida State University, and New College University in figure 4.1 offer a hint at the future should statewide marketing efforts be revived.

\section{Lessons learned/Looking ahead}

UBorrow currently only manages to fill $64 \%$ of patron requests on average. This is in stark contrast to the GWLA recommended $85-95 \%$ fill rate for borrowing in resource sharing. A low fill rate can be directly linked to a limited collection of materials and a high local demand for items at each university. The low instance of patron's moving their request to the interlibrary loan system (1\% at USF; $5 \%$ at New College) indicates that the user sees the UBorrow cancellation as a dead end. Whether they are satisfied with this option may be linked to their knowledge of available resources. Whether libraries should be satisfied with this brick wall may be something that needs more emphasis on the UBorrow development priority list.

The average supply rate of $55 \%$ among lender libraries after the first year also needs consideration. This is due primarily to the almost one quarter of participating libraries not filling most or all of the requests that get sent them. These collections are only delaying patron requests from finding a lender. A review of the available collections, load leveling and policies could improve this situation. It might also alleviate increased lending workload at smaller institutions, as seen at NCF.

UBorrow is intended to be a great service, and like all great services, it must be in a 
state of constant improvement. Patron satisfaction is at the heart of this mission. To this end the UBorrow Development priorities list gives libraries and users a peek into future modifications some of which include enhancing the UBorrow request button display and a plan to prevent requests going to non-lenders (FCLA, 2012). Continuing development faced new challenges in the reorganization of preexisting technical support centers across the state into a new service organization called the Florida Virtual Campus (FLVC) (FCLA, 2012).

No additional money was directed toward the development and launch of UBorrow, and staffing levels at participating institutions remained the same since the launch of the service in 2011. The new cooperative state university and college system, organized during the creation of the Florida Virtual Campus, meant the opportunity for UBorrow to expand. State colleges also used the ALEPH ILS and in February 2014 were added as potential lenders in UBorrow as the first step in a multi-phase merger. Future phases would include the holdings of the state colleges in the shared UBorrow catalog in conjunction with the launch of a shared statewide discovery tool. A committee of access services and interlibrary loan representatives from the universities and colleges, the FLVC Resource Sharing Standing Committee, was tasked with improving the existing systems and recommending new ways libraries across the state could cooperatively perfect resource sharing. Discussions about the future of UBorrow include lending media items, though agreement has not yet been reached on how long these items should circulate. These two new developments, the addition of state college holdings to the existing UBorrow system and the possibility of adding media, are contributing to increased complexity in the service. Items in UBorrow will no longer have the same due date and the same possibility for renewal no matter the lender. The FLVC Resource Sharing Standing Committee is also responsible for reviewing and updating the UBorrow policies developed for the launch of the original service.

\section{Conclusion/Result}

The merger of the pre-existing statewide technical support centers, the Florida Center 
for Library Automation that serviced the universities, and the College Center for Library Automation that serviced the state colleges, delayed analysis, evaluation, and review of the UBorrow service and the policies it launched under. This may have also contributed to the leveling off of UBorrow traffic since the launch of the service. It is clear that marketing and promotion of the service is a key to the success of this cooperative lending program. As with other library programs, there must be continued focus on educating new students, faculty and researchers as you would with other library literacy programs. There must also be an effort to service review and improvement. These efforts must ensure that hindrances to the fulfillment of requests should be monitored and corrective action be taken to ensure improvement.

The new environment of expanded cooperation offers exciting possibilities and a much larger state wide library collection of access to UBorrow users. However, the inconsistent due dates and policies will probably cause initial confusion to users and, in the end, hamper the success of the system as a whole. The FLVC Resource Sharing Standing Committee's work on a set of shared policies becomes the most important part of future developments. UBorrow always has had the potential for adding more institutions similar to other programs like OhioLink. However, growth must be managed and supported to ensure that service delivery is maintained and improved for all participants. It is important that standardized policies, improved workflows and funding be provided so that there can be a baseline for the service. Experience has shown that inconsistent policies and low fulfillment rates could ultimately prevent this resource sharing program from achieving true success. 


\section{References}

BLC, Ebrary, YBP partner for E-book pilot. (2012). Advanced Technology Libraries, 41(11), 6-6. Retrieved from http://ezproxy.lib.usf.edu/login?url=https://search.ebscohost.com/login.aspx?direct=true\&d $\underline{b}=|| f \& A N=83393836 \&$ site $=$ eds- live

Cook, A., \& Smith, D. J. (2011). The ohio library and information network: Resource sharing at its best. J ournal of Interlibrary Loan, Document Delivery \& Electronic Reserves, 21(5)

Fennewald, J. (2005). PALCl's virtual union catalog: Sharing the wealth. J ournal of Library Administration, 42(1), 63-78. doi: 10.1300/J 111v42n01-04

Florida Center for Library Automation (FCLA). (2012). Background on UBorrow pilot project..

Florida Center for Library Automation (FCLA). (2012). Florida virtual campus. Retrieved, 2014, Retrieved from https://fclaweb.fcla.edu/node/5263

Florida Center for Library Automation (FCLA). (2012). Top development issues. Retrieved, 2014, Retrieved from https://fclaweb.fcla.edu/node/3902

Niu, X., Hemminger, B. M., Lown, C., Adams, S., Brown, C., Level, A., . . Cataldo, T. (2010). National study of information seeking behavior of academic researchers in the united states. Journal of the American Society for Information Science and Technology, 61(5), 869-890. doi: 10.1002/asi.21307

Schmidt, L., \& Smith, D. (2012). The florida state libraries resource sharing initiative: Unity among a disparate group. J ournal of Interlibrary Loan, Document Delivery Electronic Reserve, 22(1), 9-15.

Smith, F. (2012). GIL express in georgia: An interlibrary Loan/Circulation hybrid for circulating books. Journal of Interlibrary Loan, Document Delivery Electronic Reserve, 22(2), 73-81. 
University of South Florida. (2014). Common data sets 2013-2014 tampa \& lakeland campus.

Retrieved, 2014, Retrieved

from http://usfweb3.usf.edu/infocenter/Surveys/cds/CDS2013_2014_Tampa.pdf 


\section{UBorrow Comments: content}

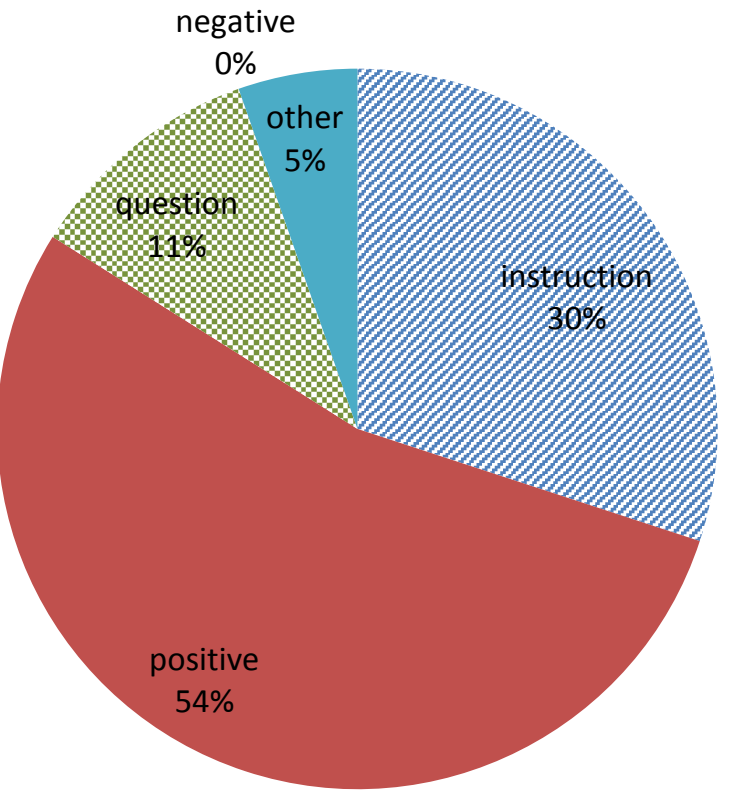

<Fig. 1.1 caption: comments from UBorrow patrons from 3/2011 to 1/2012>

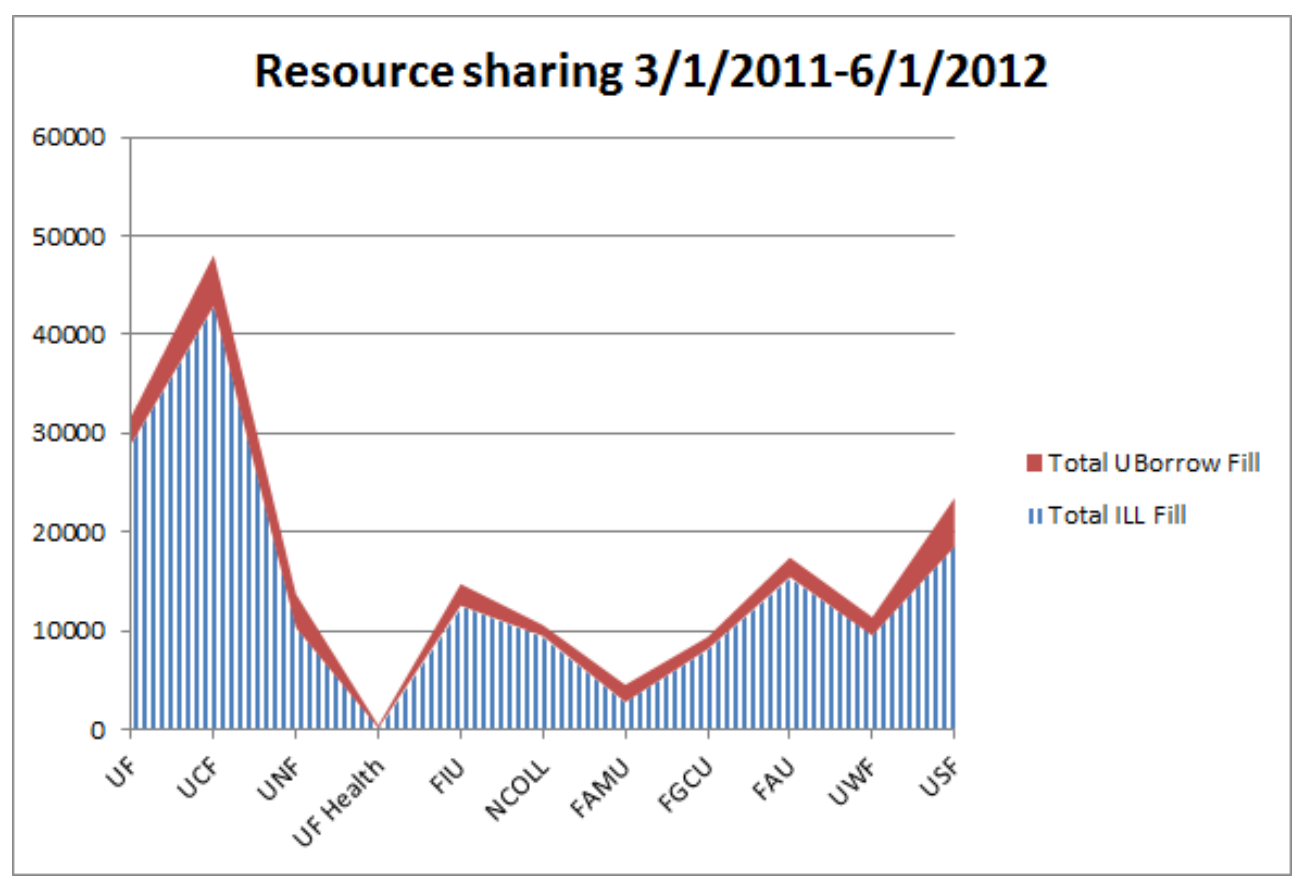

<Fig.1.2 caption: Traditional ILL and UBorrow traffic among the Florida State Universities> 


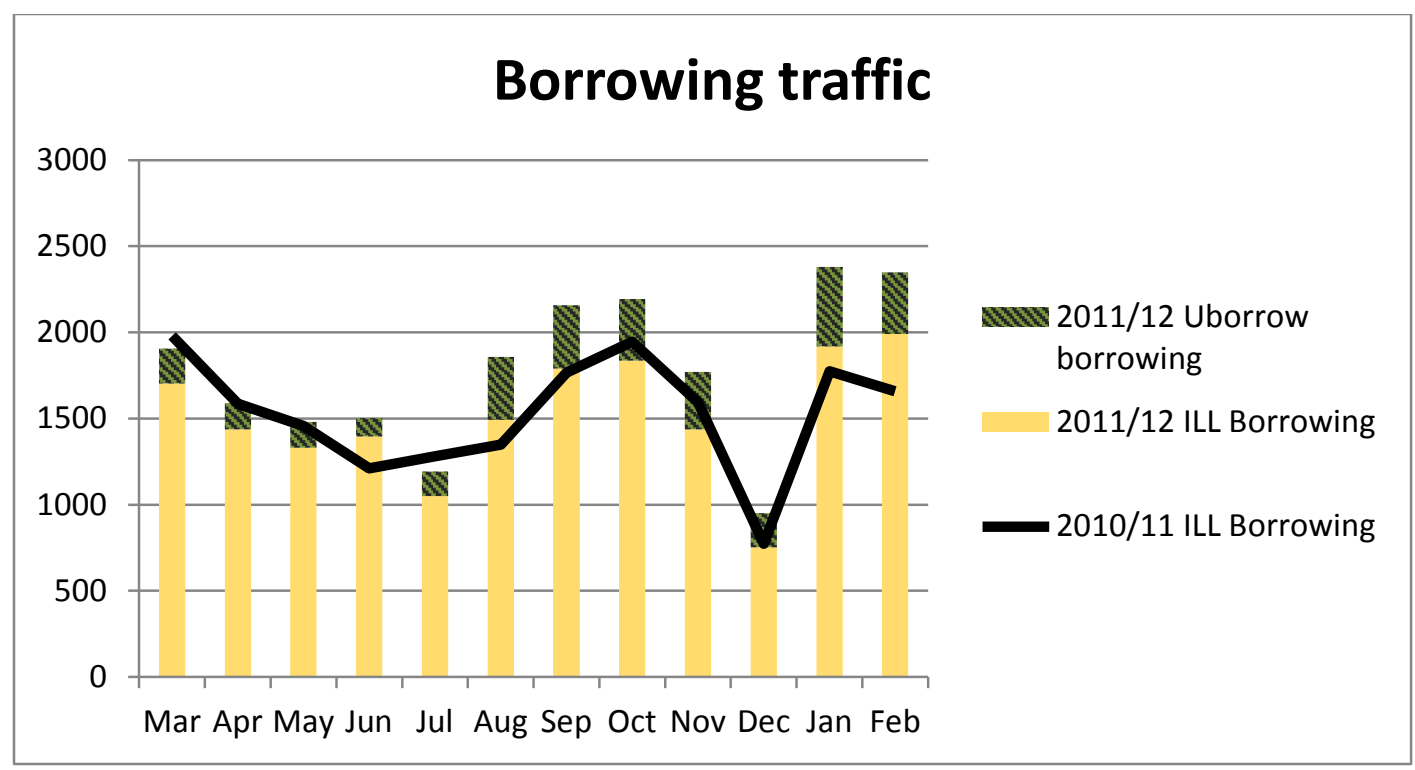

<Fig. 2.1 caption: comparing the levels borrowing traffic at the University of South Florida a year after UBorrow launch with the previous year>

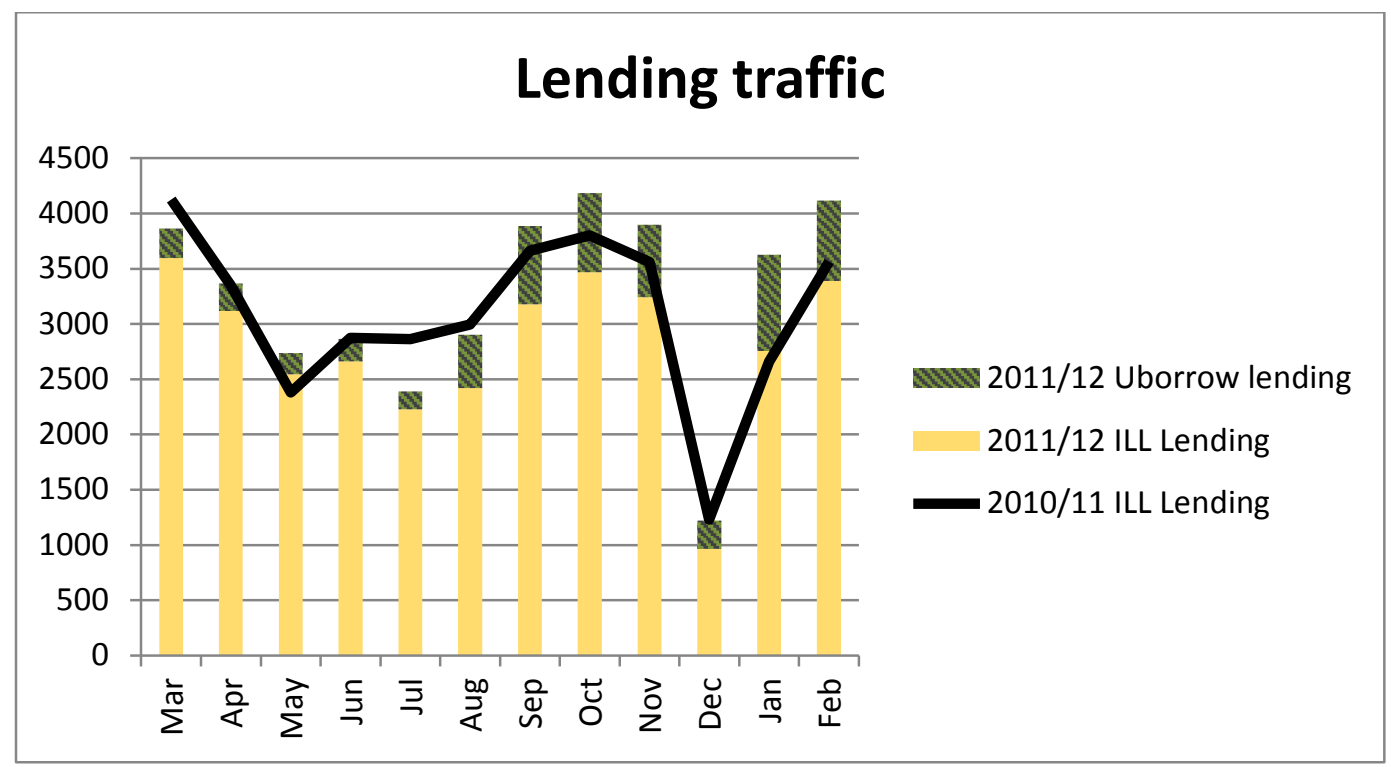

$<$ Fig. 2.2 caption: comparing the levels of lending traffic at the University of South Florida a year after UBorrow launch with the previous year> 


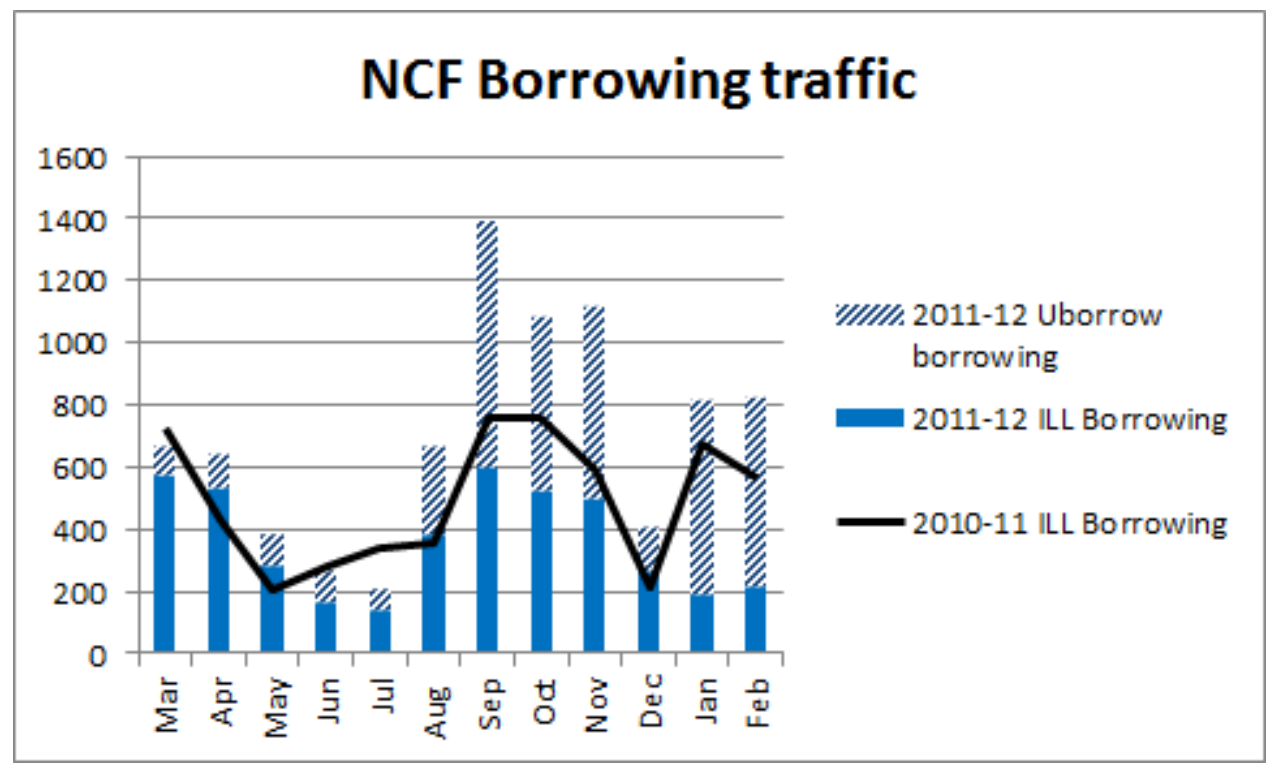

<Fig. 3.1 caption: comparing the levels borrowing traffic at New College of Florida a year after UBorrow launch with the previous year>

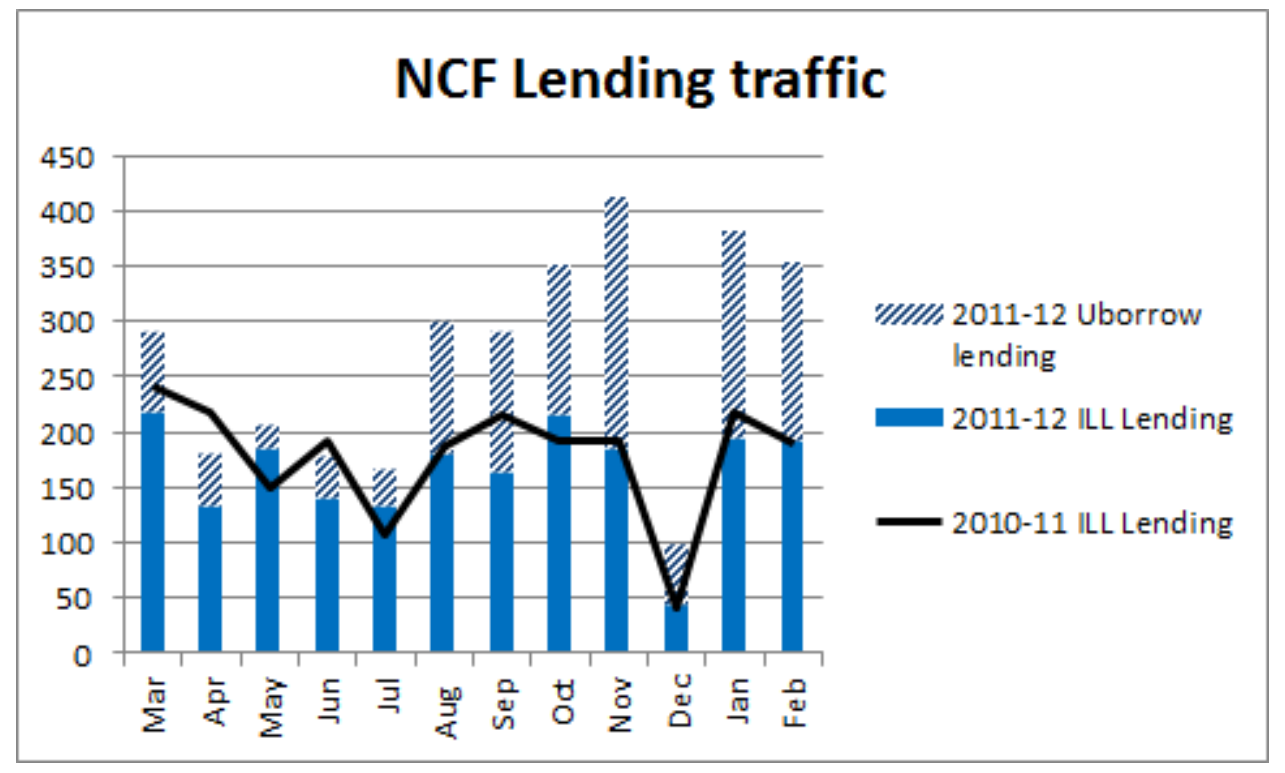

$<$ Fig. 3.2 caption: comparing the levels of lending traffic at New College of Florida a year after UBorrow launch with the previous year> 


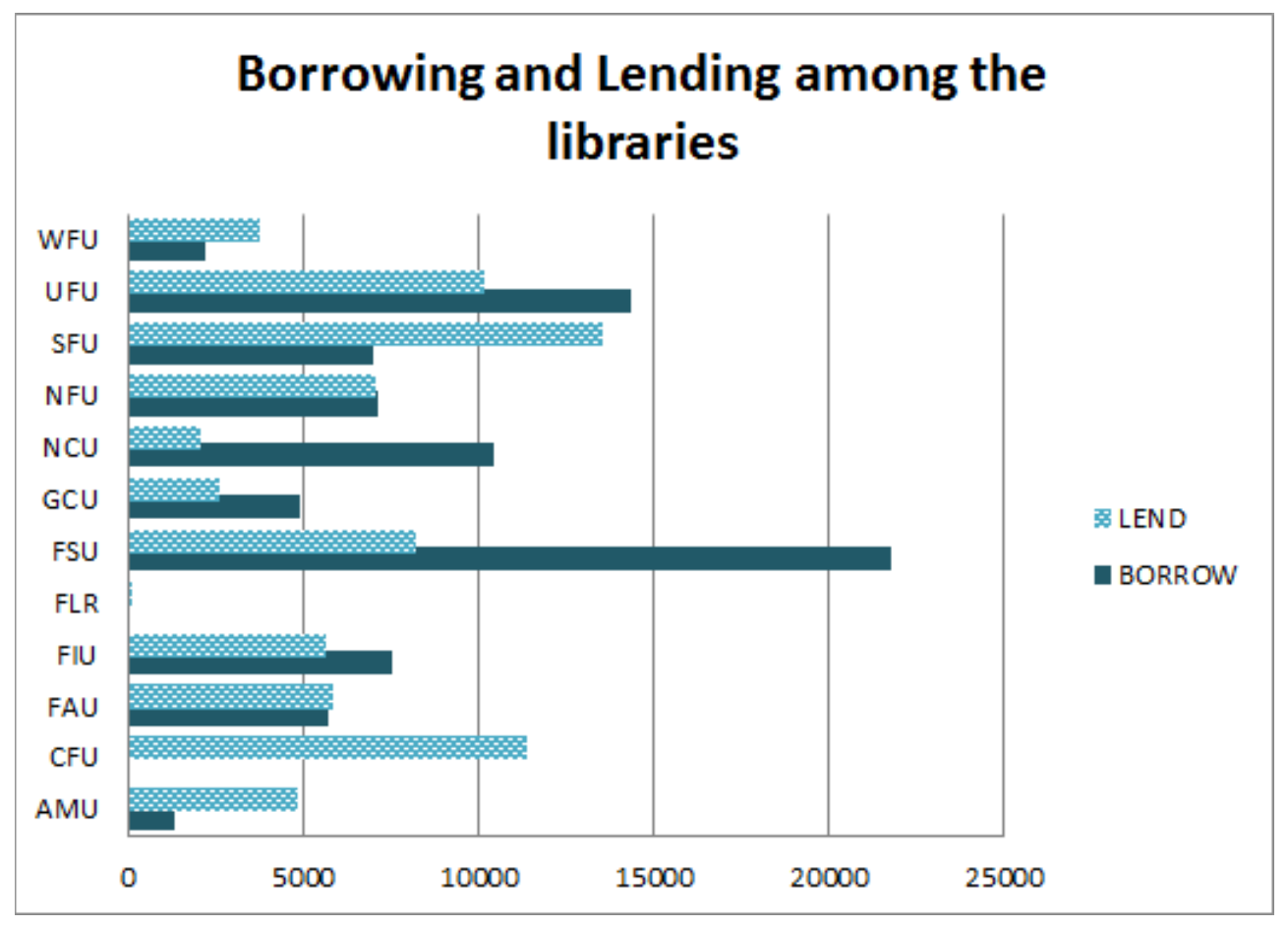

<Fig 4.1 caption: Borrowing and Lending rates among the among the Florida University Libraries since UBorrow launched>

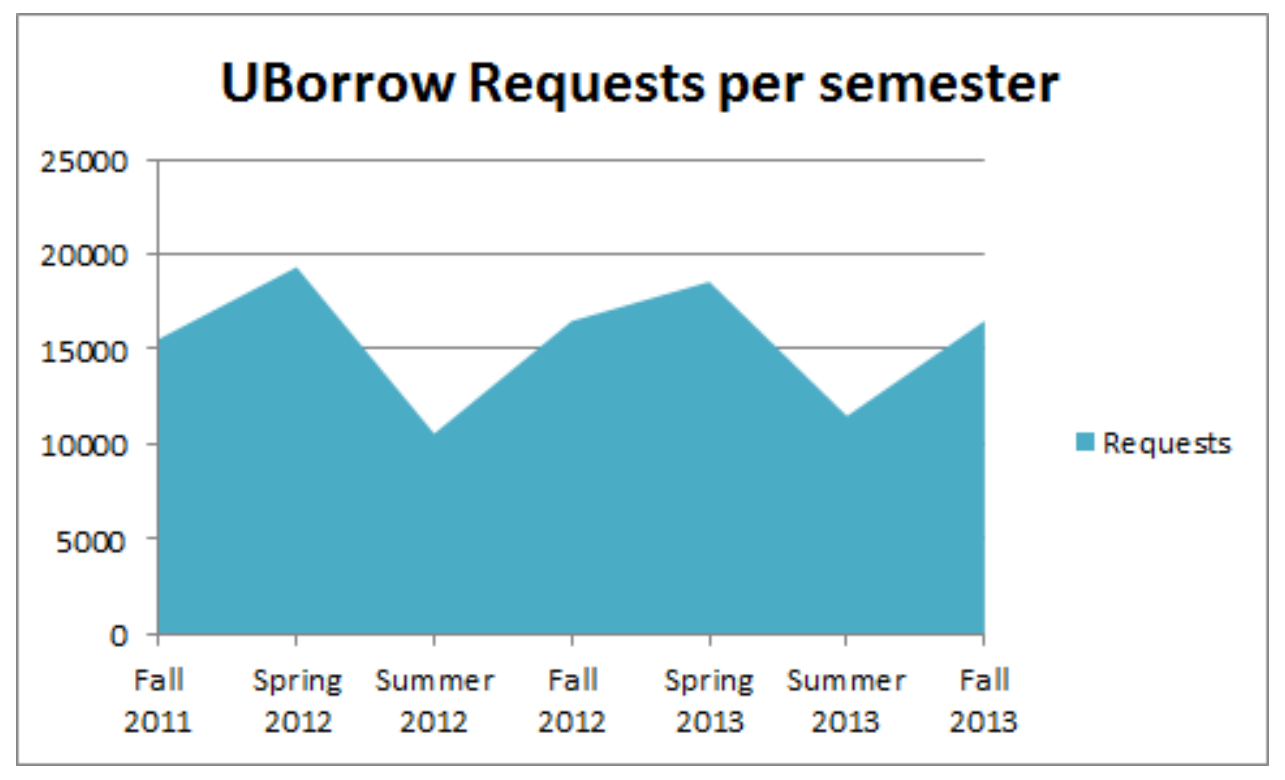

<Fig. 4.2 caption: UBorrow requests sent to lenders by the system by semester> 